\title{
De pintar las medianeras al diseño de un museo al aire libre. Puerto Street Art, un espacio abierto a la creatividad
}

\author{
Carmen Milagros González Chávez ${ }^{1}$ | Ana María Quesada Acosta ${ }^{2}$
}

Recibido: 04-17-2020 | en su versión final: 22-07-2020

Resumen

Puerto de la Cruz, municipio tinerfeño, ha diseñado un singular museo al aire libre cuyas "salas" recogerán desde pinturas murales a esculturas, pasando por intervenciones creativas en mobiliario urbano. Nuestro objetivo es documentar ese proceso cultural para difundir el modelo de gestión, así como las estrategias que se han propuesto desde que surge la iniciativa hasta la actualidad. Nuestro método, tras un primer trabajo de campo en el que clasificamos las distintas intervenciones realizadas, consistió en consultar las fuentes oficiales que nos proporcionaron miembros del Consorcio Urbanístico para la Rehabilitación de Puerto de la Cruz, distintas memorias que nos enriquecieron, durante una entrevista, con aportaciones personales. Dado que la propuesta, pese a derivar en vocación museística, lleva consigo el posible carácter efímero de algunos murales, además de documentarlos, pasamos a comentarlos desde una perspectiva crítico artística, explorando en la variedad temática y técnica. Para ello recurrimos en algunos casos también a entrevistas y a las páginas web de los artistas implicados, ya que su continua actualización por parte de los mismos, nos garantizaba estar al día sobre su trayectoria $u$ otras intervenciones similares. Analizadas otras acciones, consideramos que el interés de nuestro trabajo contribuye a poner en valor una de las pocas iniciativas que se han llevado a cabo en Canarias encaminadas a mejorar el entorno urbano y que puede servir de modelo a otras localidades, una propuesta que hasta ahora no ha sido abordada por ninguna otra investigación, lo que garantiza su originalidad.

Palabras clave: Grafiti; mural; espacio público; vecino

Citación

González Chávez, C. y Quesada Acosta, A. (2020). De pintar las medianeras al diseño de un museo al aire libre. Puerto Street Art, un espacio abierto a la creatividad. ACE: Architecture, City and Environment, 15(44), 9271. DOI: http://dx.doi.org/10.5821/ace.15.44.9271

${ }_{1}$ Profesora Titular del Departamento de Historia del Arte y Filosofía de la Universidad de La Laguna. (ORCID: $\underline{0000-0002-5182-3563})^{2}$ Profesora Titular del Departamento de Historia del Arte y Filosofía de la Universidad de La Laguna. (ORCID: 0000-0002-5588-8292). Correos de contacto: cmgonzal@ull.es, aquesada@ull.es 


\title{
From painting street walls to designing an open-air museum. Puerto Street-Art, a space open to creativity
}

Abstract

\begin{abstract}
Puerto de la Cruz, a municipality of Tenerife, has designed a unique open-air museum whose "rooms" will include everything from mural paintings to sculptures, as well as creative interventions in urban furniture. Our objective is to document this cultural process in order to disseminate the management model, as well as the strategies that have been proposed since the initiative arose to the present day. Our method, after initial fieldwork in which we classified the different interventions carried out, consisted of consulting the official sources provided by members of the Urban Planning Consortium for the Rehabilitation of Puerto de la Cruz, whose different memories enriched us, during interviews, with their personal contribution. Given that the proposal, despite being derived from a museum perspective, carries with it the possible ephemeral nature of some murals, in addition to documenting them, we went on to comment on them from an artistic critical perspective, exploring their thematic and technical variety. To do this, in some cases we also used interviews and the websites of the artists involved, as their continuous updating guaranteed that we were up to date on their careers and other similar interventions. Having analysed other actions, we consider that the interest of our work is that it contributes to the value of one of the few initiatives that have been carried out in the Canary Islands aimed at improving the urban environment and that can serve as a model for other localities, a proposal that has not been addressed by any other research until now, which guarantees its originality.
\end{abstract}

Keywords: Graffiti; mural; public space; neighbors

\section{De paredes inertes a lienzos pictóricos}

\subsection{La propuesta inicial. Idea y promotores}

Puerto de la Cruz es el municipio más pequeño de Tenerife, pero ello nunca ha supuesto un obstáculo para su desarrollo local, destacando ancestralmente en la economía tinerfeña dadas sus óptimas condiciones geográficas. Su estratégica situación, en la costa del Valle de La Orotava, lo convirtió en un enclave comercial relevante que durante siglos se mantendrá activo, gracias a las exportaciones que sostiene particularmente con Gran Bretaña, lo que favorece el asentamiento de una burguesía que focaliza sus intereses en torno al comercio. Por otra parte, la benignidad de su clima lo transmuta desde principios del ochocientos, en un atractivo foco turístico al que comienzan a llegar extranjeros, huyendo de las rigurosas temperaturas europeas, con objeto básicamente de intentar sanar sus dolencias1. Estos turistas serán los antecedentes de una actividad económica que se incrementa a mitad del siglo pasado, concretamente a partir de 1955,

\footnotetext{
1 Fue precisamente la benignidad de su clima, lo que convirtió a Puerto de la Cruz en centro turístico pionero de Canarias, sobre todo a raíz de que la Sociedad Médica Británica, en el siglo XIX, lo recomendara para la recuperación de determinadas enfermedades.
} 
año en el que el término municipal es declarado "Lugar de Interés Turístico". Desde entonces, la fisonomía de la ciudad comienza a cambiar y junto a las casonas históricas y casas terreras que tanto singularizaban, particularmente a las calles de La Ranilla, antiguo barrio de pescadores, comienzan a erigirse inmuebles de altura superior, con el ánimo de acoger al mayor número posible de visitantes.

Esta introducción que puede resultar baladí al lector, se nos antoja del todo necesaria, ya que precisamente justifica el interés con el que Puerto de la Cruz expone y emprende en 2014, su propuesta de arte urbano. Partiendo de la base de unos excelentes recursos, arquitectura tradicional y clima benigno que permite largos y tranquilos paseos, sus promotores idean un innovador producto turístico que debe mucho, tanto a su anhelo por renovar este sector económico, como al de recuperar el papel cultural que desde la Ilustración había convertido al lugar en un punto señero de la isla. Además, con ello solucionaban un antiestético problema que definía la fisonomía del núcleo, resultado de la desigualdad constructiva impuesta por la eclosión del turismo de masas: las antiestéticas medianeras. Pese a que este inconveniente se había detectado desde hacía años en distintos planes urbanísticos, estos no aportaban grandes soluciones, y menos aún se había contemplado la posibilidad de que estas pudiesen radicar en un proceso artístico, medida sugerida en primera instancia por el equipo de Arquitectura, Urbanismo y Colaboración que, bajo la dirección de la arquitecta María Luisa Cerrillo, emprende el Plan Especial de Protección del Puerto de la Cruz (PEPCH), años después de que este fuese declarado, en 2006, Bien de Interés Cultural en la categoría de Conjunto Histórico² (Consorcio Rehabilitación Puerto de la Cruz, 2014). En efecto, aunque dicho documento urbanístico continúa hoy en día sin aprobarse, no podemos obviar que resultó el detonante para solventar un problema al que finalmente se va a enfrentar el Consorcio Urbanístico para la Rehabilitación de Puerto de la Cruz, órgano que confía el proyecto a Alberto José Gutiérrez, a la sazón, Arquitecto Técnico Municipal, quien desde la oficina de la que es titular y, en colaboración con personal adscrito a la Concejalía de Cultura y Mujer, elabora el "Proyecto piloto de mejora del entorno urbano mediante intervenciones artísticas en medianeras. Puerto Street-Art". Una vez aprobado, su implementación se acoge al denominado Plan de Modernización Mejora e Incremento de la Competitividad de Puerto de la Cruz, inserto a su vez en el denominado Programa de Gestión y Planificación ${ }^{3}$ (Consorcio Rehabilitación Puerto de la Cruz, 2014).

Enunciados ya los objetivos generales de esta tentativa, la memoria recoge también otra serie de propósitos específicos, todos encaminados a potenciar el trinomio arte-cultura-turismo, a fin de que revirtiera en la imagen de la ciudad e impulsará su desarrollo local. Entre estas segundas intenciones que, no se entienden sin las ya indicadas, destacamos las de promocionar el arte en la calle, redescubrir el núcleo como un espacio óptimo para la creación, reactivar el comercio en el municipio, convertirse en un modelo de "coordinación y trabajo conjunto entre administraciones", "adaptar las políticas culturales a los conceptos de modernidad”, ofertar mediante el arte, perspectivas de integración a los extranjeros que residían en el término, e "instrumentalizar el arte como alternativa para la juventud” (Consorcio Rehabilitación Puerto de la Cruz, 2014). Las ideas

\footnotetext{
2 Hay que hacer constar que al contrario de lo que ocurrió en otros municipios españoles, Puerto de la Cruz procuró a través de distintos planteamientos urbanos, que la implementación del turismo afectara lo menos posible en la estructura física del núcleo histórico. Su expansión, en tal sentido, fue regularizada por un documento entonces novedoso, el Plan General de Ordenación Urbana (PGOU) de 1958, al que seguirían distintos planes parciales y un nuevo PGOU en 1974, readaptado entre 1978 y 1979 y, finalmente supervisado en 1985. Diez años después, se aprobaba una revisión que debe mucho al texto refundido de las leyes de Ordenación y Espacios Naturales de Canarias, aprobado por decreto 1/2000, de actual vigencia.

${ }^{3}$ Los miembros fundadores del Consorcio Urbanístico para la Rehabilitación de Puerto de la Cruz son el Cabildo de Tenerife y el Ayuntamiento de Puerto de la Cruz; asimismo, son miembros de derecho, la Administración General del Estado, a través del Instituto de Turismo de España (TURESPAÑA) del Ministerio de Industria, Turismo y Comunicación (hoy Ministerio de Industria, Energía y Turismo) de la Administración Pública de la Comunidad Autónoma de Canarias, a través de la Consejería de Turismo del Gobierno de Canarias (Viceconsejería de Turismo).
} 
expuestas nos permiten deducir que conocían las premisas que, en materia de arte público, esgrimían distintos teóricos, entre ellos, Gómez, quien desde años antes indicara: Capacidad creativa, cooperación interdisciplinar, participación ciudadana, coordinación administrativa y cultural del proyecto están llamados a converger tanto en el planteamiento urbano como en la recualificación, de modo que la polivalencia y el potencial creativo de los equipos equilibren y enriquezcan las propuestas, en el diseño de espacios públicos (2004).

Para consolidar el proyecto se barajan tres clases de actuación diferentes, todas relacionadas con el ámbito artístico, que ya contaban con experiencias previas en otras localidades europeas. La primera, se basaba en el desarrollo de jardines verticales, opción descartada por los gastos e inconvenientes que podrían provocar a los propietarios de los inmuebles. La segunda, sugerida tan solo para el barrio de San Telmo, proponía "la integración de la medianera en el diseño del edificio mediante falsas fachadas", estableciendo carpinterías, a modo de trampantojos, que ilusoriamente sugiriesen la presencia de elementos arquitectónicos definitorios del ámbito constructivo, si bien eran conscientes, de que esta medida no resultaba recomendable para todo el municipio, en cuanto que de no envejecer los materiales de forma adecuada, podrían surgir, en el futuro, consecuencias poco afortunadas y para nada deseadas, razón por la que se deja pendiente, para en su caso, aplicar, de ser posible, también en otros puntos. La tercera alternativa, la que finalmente resultará elegida, ve en la medianera el soporte adecuado para desarrollar un arte que, sin competir visualmente con los elementos históricos preexistentes, potenciase la personalidad del centro histórico, opción que interpreta el muro como un gran lienzo en el que determinados artistas pudiesen intervenir, siendo conscientes de que las recreaciones tendrían, con toda probabilidad, una existencia efímera. Llegados a este punto, quizá conviene puntualizar que en todo momento se refieren a una pintura mural consentida, más o menos narrativa y programada, lejos por tanto del grafiti clandestino, transgresor y espontáneo, pese a que muchos de los artistas que la cultivan han ejercido o incluso simultanean también esta práctica, de ahí que gusten denominarse tanto muralistas como grafiteros, términos que por tal motivo, pese a encerrar ciertas diferencias, también utilizamos en el texto de forma indistinta. La diferencia entre ambas prácticas, la explica perfectamente Muñoz en su tesis doctoral, al señalar que "un graffitero que sabe que está afirmando su personalidad, el publicista que sabe que está vendiendo un producto y el muralista que sabe que está ofreciendo una obra de arte a la ciudad" (1993, p.44).

No sorprende que fuese esta la opción ganadora, ya que como acertadamente se reconoce en la memoria, alternativas similares se habían puesto en marcha con éxito, en diferentes núcleos urbanos. En España, podemos traer a colación, los proyectos emprendidos en el barrio barcelonés El Raval, en el valenciano El Carmen y, el materializado en el casco histórico de Zaragoza, proceso este último minuciosamente estudiado por Henar (2000). Aunque se dieron casos aislados en fechas previas, podemos indicar que, en las islas, la necesidad de ensanchar los contextos artísticos y el reconocimiento de la función social del espacio público por parte de creadores y políticos se iniciaba en los ochenta. El Ayuntamiento de La Laguna, presidido por el pintor Pedro González, protagoniza un ejemplo (1986), al encargar un mural a Juan Hernández y otro a Gonzalo González, con el fin de conferir identidad a la por entonces desfavorecida calle Heraclio Sánchez. Por esos años, también las Palmas de Gran Canaria se enriquecía visual y socialmente, si bien nos parece más interesante resaltar la intervención destinada a dignificar las medianeras del Paseo Playa de Las Canteras (1993-1994) (Armas, J.J., 1995). Denominada "Canteras Viva-Atlántico Sonoro", por estar inspirada en un poema de Tomás Morales, fue propuesta por el Consistorio a Fernando Álamo, Manolo Padorno y a García Álvarez. Este último participará en la ornamentación de las instalaciones industriales de Cepsa en Santa Cruz de Tenerife (1999), donde previamente había intervenido en otros puntos Severo Acosta (1988) (T. G., 2009; Castro, F., Peralta, Y. y Quesada, A. Maㅡ, 2011; Dávila, J., 2010). 
En 2000, el Área de Infraestructura y Servicios del Ayuntamiento de esta última ciudad, emprende un proyecto dirigido por el artista Fernando Larraz Mora, con el que se ornamentaron diversos centros docentes y de ocio localizados en distintos barrios, entre ellos, el Grupo Escolar Teniente General Rodríguez, ubicado en Ofra. Años después (2016) acometería su restauración ("El muralista Fernando Larraz coordina la recuperación”, 2016). Son suyas también las pinturas recreadas en los muros perimetrales de Unelco, en Cabo-Llanos, sector sometido esos años a una importante renovación urbanística (Larraz, F., García, Ma A., 2000). Sin embargo, la iniciativa más llamativa del Archipiélago, correspondió por entonces (1999), al Foro de Arte Contemporáneo (CEMFAC), que en Los Llanos de Aridane impulsó La Ciudad en el Museo, propuesta que, a diferencia de las anteriores, no trata de intervenciones directas en las medianeras, sino sobre grandes paneles de contrachapado fenólico e hidrófugo que son literalmente colgados sobre estas (Suárez, R. (coord.), 2007). Cabe destacar, por ofrecer formatos más afines a los que propondrá la localidad portuense, el efímero Festival de Arte Urbano que promovió el municipio grancanario de Ingenio, en la playa El Burrero (Ariza, A., 2008), así como, el Festival Rural de Creación-Las Eras del Tablero, en Tenerife (Festival Rural de Creación- Las Eras del Tablero). Y la tentativa que, en la capital de esta misma isla, se viene desarrollando desde 2012, bajo el título Sumérgete en Santa Cruz. (González Chávez, C. M. y Quesada, A. Mạ., 2020). De todas ellas, sin duda, esta última es la que mayor repercusión ha alcanzado, debiéndose a una iniciativa que parte de Belén Machado, responsable de Comunicación y Relaciones Corporativas de la Compañía Cepsa, quien, tras viajar por Europa, donde contempla el street art de distintas ciudades, propone a la sociedad poner en práctica un proceso que impulsara esta actividad.

Con la colaboración activa del Ayuntamiento, y la dirección artística del muralista Iker Muro, la idea se viene materializando sobre grandes paredes ciegas (Machado, B., 2018). Al año siguiente, Las Palmas de Gran Canaria, gracias al patrocinio del Ayuntamiento y de distintas entidades, como Caixa o Cepsa, entre otras, y a la colaboración de la plataforma Streetarter.com, celebraba el I Concurso Internacional de Arte Urbano, en el marco del TEMUDAS Fest Festival. Más de treinta artistas intervinieron sobre quince paredes, tres muros de exhibición, y un contenedor ecovidrio.

Suponemos que fueron todas estas experiencias previas, y algunas más que no incluimos para evitar una relación que puede resultar cansina, las que de un modo u otro les hace afirmar a los promotores, en la memoria, la idea de que en Canarias existía una clara relación entre arte urbano e idiosincrasia cultural, un factor sociológico que a nuestro juicio le otorga mayor interés al proyecto, y que ha marcado su singularidad, al intentar poner el acento en el uso diferenciador que el canario, frente al individuo de otras sociedades, hace de la vía pública. En opinión de los responsables, en el Archipiélago, por razones también climáticas, se mantiene la tradición del uso del espacio como lugar para las relaciones de intercambio entre las personas; de ahí que en procesos democráticos "el uso natural del espacio público habría de generar una dinámica cultural de intervención artística en aquellos momentos en los que se produce la ocupación ciudadana de los lugares comunes de convivencia, o sea siempre" (Consorcio Rehabilitación Puerto de la Cruz, 2014).

Dicho de otro modo, la emergencia de que los artistas pudiesen comunicarse en un espacio que nos pertenece a todos, actuando de forma abierta, en momentos en los que el público sale a la calle en busca de todo tipo de experiencias plásticas, diferentes a las que habitualmente vive, es indiscutiblemente mayor que la posibilidad que tendrían en otras zonas de climatología más rigurosa. Este hecho supone un revulsivo que signa la excepcionalidad de la vida cotidiana del lugar, y favorece la puerta de la comunicación entre los dos polos, creador y espectador, permanezca abierta por mucho más tiempo. Por otra parte, este diálogo convertiría "a esta ciudad atlántica, mestiza y catalizadora de tendencias”, en un escenario al aire libre que integraría al municipio en los valores culturales de las sociedades modernas, transformándolo en un lugar de culto artístico, generado no solo por creadores de prestigio, sino también por artistas emergentes. 
Antes de ultimar la memoria del proyecto, los promotores habían verificado un reconocimiento del núcleo para seleccionar aquellas medianeras susceptibles de acción, pero en función del considerable número que identificaron se propone darles viabilidad en distintas fases, atendiendo en primera instancia a aquellas que en su opinión resultaban prioritarias. Por ello aducen que en cada etapa se acometería una cantidad previamente determinada, en función de los recursos disponibles y de una serie de criterios invariables: actuar en inmuebles resaltados en el PEPCH, o en su defecto, en aquellos, que localizados fuera de los límites del perímetro histórico, reclamaran por su estratégica situación una modificación estética, así como, contar con la implicación de los propietarios afectados, recordando que por encima de la legitimidad de la empresa regiría siempre el régimen legal de la propiedad. Partiendo de estos supuestos y en previsión de que algunos de los inmuebles presentaran objeción de cualquier naturaleza, debía siempre seleccionarse un número de paredes superior.

Desde el punto de vista técnico, en su opinión, no podía perderse de vista que las intervenciones, sin menoscabo de su valoración artística, debían considerarse "pintura de fachadas", por lo que resultaba imprescindible someter las paredes previamente a una valoración técnica, en busca de posibles grietas o desperfectos. El saneamiento de las defectuosas se haría aplicando morteros y masillas, compuesto posteriormente raspado y sellado que serviría de base a una pintura en color liso que actuaría como soporte de la plástica. En realidad, esta cuestión respondía al deseo de que, pese al carácter efímero de las obras, estas permaneciesen en correcto estado, como mínimo, entre 8 y 10 años, tiempo que garantizaba su amortización económica, antes de que retornaran a la localidad para volver a ser intervenidas (Consorcio Rehabilitación Puerto de la Cruz, 2014).

No podemos perder de vista que el proyecto se concibe no solo como producto turístico ya elaborado, sino también como un recurso, de ahí que el proceso de ejecución sea tan interesante y atractivo como el resultado final. Reparemos en que es el momento en el que convergen espectador y artista, favoreciendo el diálogo del que antes hablábamos. Por ello, no nos sorprende que, al tratarse precisamente de un programa organizado también para un público foráneo, este requiriese como es habitual en este tipo de eventos, de un calendario de actuación fijo, ya que está comprobado que, disponiéndose la fecha con antelación, se garantiza mayor afluencia de visitantes. Si esa agenda contiene además otros acontecimientos culturales consolidados, el éxito de la iniciativa tendrá muchas posibilidades.

Por ello, desde esta primera edición, Puerto Street-Art 2014, arrancaría en dos fases, en atención a dos eventos culturales que ya contaban con notable difusión. El primero es MUECA, Festival Internacional de Arte en la Calle, a celebrar en la segunda semana de mayo, cuya primera edición data de 2002 y que interpreta, precisamente, el espacio público como escenario de una propuesta cultural singular, en la que interactúan ciudadanía, creadores y visitantes que, desplazándose a través de distintos ámbitos del núcleo, pueden disfrutar de diversas actividades, teatro, música, danza, artes plásticas... (Festival Mueca, 2019)4 .También transita por el núcleo histórico, el segundo de los eventos elegidos como marco temporal del proyecto que estudiamos, a celebrar entonces en septiembre, aunque actualmente tiene lugar en octubre, PERIPLO, Festival Internacional de Literatura de Viajes y Aventuras Puerto de la Cruz, temática que enlaza con la identidad del municipio, epicentro de los primeros viajeros que arribaron a Tenerife (Festival Periplo, 2007) ${ }^{5}$

\footnotetext{
${ }^{4}$ Este festival está organizado por el Ayuntamiento de Puerto de la Cruz, Cultura de Puerto de la Cruz, y Plataforma Cómplice, con la colaboración del Cabildo de Tenerife. La Plataforma Cómplice reúne a todas las empresas que de un modo u otro prestan su apoyo al proyecto, reflejo del espíritu participativo del Festival, haciendo que todo fluya con normalidad.

${ }^{5}$ Organizado también por el Ayuntamiento de Puerto de la Cruz se enmarca, al igual que MUECA y Puerto Street Art, dentro de la Estrategia Cultural de Puerto de la Cruz. La colaboración de empresarios, vecinos, activistas culturales del Puerto y representantes políticos se canaliza en este caso a través del denominado Co-Mando Periplo.
} 
Los promotores, además de sugerir las medianeras, en ese momento un total de doce, aportan también el nombre de los artistas seleccionados, la mayoría de trayectoria reconocida. Si bien aseguraban que en un futuro darían oportunidad a artistas locales y emergentes, en esta primera edición, la elección de muralistas consolidados, respondió al deseo de que su presencia y firma resultasen un buen reclamo para conformar lo que desde un principio se interpreta como "un museo al libre para estimular la creatividad", lema que acompaña al título de la iniciativa. Y como todo museo que se preciara de serlo, se requería un coordinador, un comisario, responsabilidad que dejan en mano, con buen criterio, dado su bagaje en empresas de similar envergadura, en Matías Mata, "Sabotaje al Montaje", quien aportó su experiencia en la gestión teórica del proyecto y en la elección de autores (M. Mata, comunicación personal, 8 de junio de 2019).

\subsection{Los murales. Un itinerario a recorrer}

La iniciativa recibirá el visto bueno, de modo que en días previos a los festivales y durante la celebración de los mismos, algunas paredes de Puerto de La Cruz, concretamente cinco en MUECA y ocho en PERIPLO, ante la curiosidad y sorpresa del viandante, fueron mutando. Atrás dejan su carácter inerte para convertirse en animados murales, auténticos lienzos que plasman un amplio abanico de tendencias, en función de las preferencias estilísticas de cada autor, ya que en ningún momento se impuso ni técnica, ni temática, ni mucho menos estilo alguno, primando en consecuencia la libertad del artista ${ }^{6}$. Pasamos a comentarlos someramente, siguiendo el orden o ruta propuesta por Cultura, en un folleto ilustrativo que puede adquirir cualquier persona interesada en los puntos de información turística del municipio. Este documento resulta de gran utilidad para el visitante, ya que además de un plano con la señalización de cada uno de los murales, expresa también el título y un breve comentario de los mismos, así como el nombre de su autor (Plataforma Puerto Street Art, 2017).

Iniciamos el recorrido en la calle Mequinez, en su extremo más próximo al muelle, donde nos encontramos con dos murales. En el lado izquierdo ha dejado su impronta el danés Victor Ash (Ash, V., 2019), firmando Border to Paradise (La frontera del paraíso), (Figura 1). Preocupado siempre por los acontecimientos y forma de vida de la sociedad, aprovecha el muro para denunciar, mediante la recreación de una maya conformada por figuras humanas entrelazadas en las extremidades, los condicionantes y perjuicios sociales que limitan al hombre, impidiéndole sentirse realizado y, por ende, libre. Se trata de una forma de interpretar sus propias emociones, intentando dilucidar al mismo tiempo, como su subconsciente, tras un proceso de síntesis mental, convierte esos sentimientos en plástica?.

La individualidad del artista y la arbitrariedad temática, se pone de manifiesto, si comparamos el mural anterior con el divertido y entrañable imaginario jalonado de playmobils que despliega "Ro. Ro.", Roberto Rodríguez (Figura 2), (Rodríguez, R., 2019), justo en la medianera de enfrente, es decir, en el costado izquierdo de la misma calle. En su propuesta, titulada Ron, Ron, Ron, La botella de ron, el joven tinerfeño nos conduce a través de un universo plástico que debe mucho a su particular atracción por los bazares chinos, el color rosa y lo kitsch. Pese a lo banal que pueda parecernos, lo cierto es que nos invita también a reflexionar sobre una supuesta narración, una metáfora de la realidad vertebrada por grandes dosis de humor lúdico ${ }^{8}$.

\footnotetext{
6 En esta primera edición, los artistas que realizaron murales durante MUECA fueron Víctor Pacheco, "KOB"; Louis Lambert, "3ttman"; Raúl Ruiz, "Roa" o "El niño de las pinturas"; y Victor Ash. Los que trabajaron durante PERIPLO fueron "Belin", Miguel Ángel Belinchón; "Dulk", Antonio Segura Donat; Iker Muro, "Feol!p", Juliana Serrano, "Ro-Ro" Roberto Rodríguez y "Sabotaje al Montaje“.

7 Victor Ash nace en 1968 en Portugal; entre 1992 y hasta 1996 estudia en París y actualmente reside en Copenhague. Desde finales de los ochenta viene exponiendo en distintos museos y galerías del mundo, siguiendo distintas técnicas. En cuanto al grafiti que actualmente realiza, poco tiene que ver con el que puso en práctica durante sus primeros años en Nueva York; ahora enfrenta el entorno urbano y la naturaleza, incidiendo en uno de los problemas que más le preocupan: la búsqueda de identidad de la juventud.

${ }^{8}$ Nace en Tenerife en 1981 donde reside. Su obra se encuentra repartida en distintas colecciones; ha participado en diversas exposiciones individuales, y cuenta en su haber con galardones diversos.
} 


\section{ACE Architecture, City and Environment}

E-ISSN $1886-4805$

Figura 1. Border to Paradise

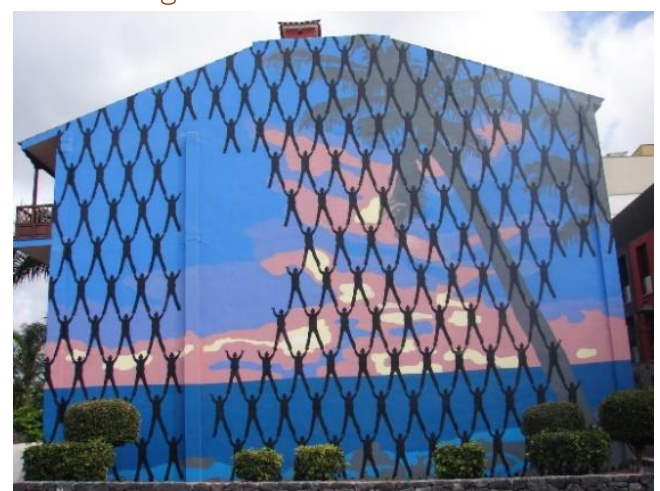

Fuente: Las autoras.
Figura 2. Ron, Ron, Ron la botella de ron

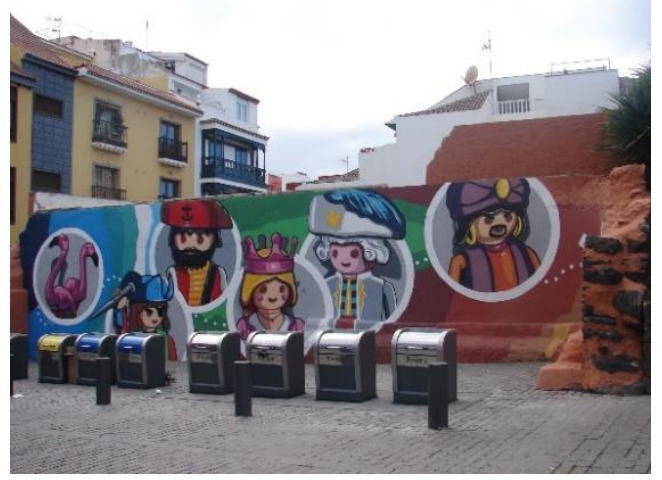

Fuente: Las autoras.

En la misma calle, pero adentrándonos en el barrio, concretamente en el número 21, Iker Muro (González, C., 2012), cuya presencia en este tipo de acontecimientos resulta hoy en día bastante habitual, recrea La Macaronesia. (Figura 3). Fiel a su estilo pop, un tanto ácido, nos lega bajo dicción surrealista y estridentes colores contrastados con negro, un personaje que parece levitar en el espacio ${ }^{9}$. Sin salir de esta arteria, situándonos en el número 66, pero con mejor perspectiva desde el callejón paralelo, e incluso desde La Placeta, Raúl Ruiz, o "El niño de las pinturas", también conocido como "Sex" (Ruiz, R., 2019), pinta una composición que contrapone una atractiva figura femenina de juvenil y moderno aspecto, con un señor que se cubre con una manta esperancera; completan el mural distintos iconos que nos remiten a la cultura aborigen, mensaje consolidado con la poética frase que da título a la pieza: La fuerza está en las raíces (Figura 4). Es precisamente la narrativa escrita, uno de los recursos que este grafitero suele incorporar a su obra como refuerzo lírico de sus siempre expresivos personajes ${ }^{10}$. A decir de Ganz, sus figuras están realizadas a base de collages de potentes colores, pintados con spray y esquemáticos rasgos, técnica que sugiere la sensación de una pintura abocetada (2008).

Figura 3. La Macaronesia

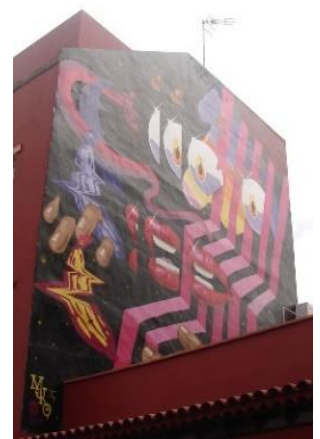

Figura 4. La fuerza está en las raíces

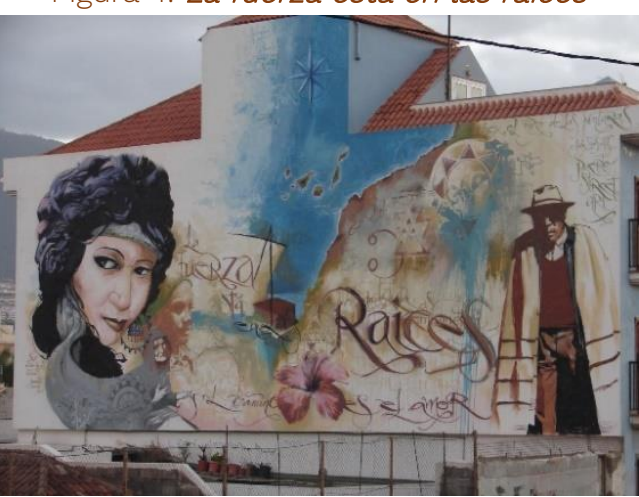

Fuente: Las autoras.

Fuente: Las autoras.

9 Iker Muro ha participado en distintos eventos de este tipo en las Islas y, actualmente es, tal como hemos comentado el director artístico y comisario del proyecto mural Sumérgete en Santa Cruz. Nació en Bilbao en 1979. Reside en Canarias desde 1992. Es diseñador gráfico, ilustrador, grafitero y muralista. En 2010 fue galardonado con el premio LAUS de diseño y comunicación de la Asociación Nacional de Diseñadores Gráficos y Directores de Arte del FAD. Ha expuesto en numerosas ciudades, Londres, Barcelona, Lisboa, Madrid, Miami e intervenido en Los Ángeles, Dakar, San Francisco y Nueva York.

${ }^{10}$ Raúl Ruiz, nació en Madrid en 1969, pero crece en Granada, de ahí que también se le conozca por la firma de "El niño de Granada”; actualmente reside en Los Realejos, Tenerife. Muestras de su producción como grafitero se encuentran en la calle de Argentina, Portugal, Francia, Venezuela, Holanda, México, Italia, Hungría o Bélgica. Es autor del libro A través del muro, una recopilación de sus trabajos más destacados. 
Sugerente y estimulante resulta tanto el título, Si puedes soñarlo, puedes crearlo, (Figura 5) como la brillante ejecución del mural que Juliana Serrano plasmó en el no 11 de la calle Maretas (Periplo, 2019). La artista portuense, única mujer que hasta el momento ha participado en el proyecto, ha recreado un escenario propio de la infancia, lleno de color y texturas, en el que se entremezclan magia y sueños ${ }^{11}$. Por el transita un vistoso y alegre elefante que porta un híbrido bebé, mitad niño, mitad sirena, que es contemplado por dos peces. Su deslumbrante colorido y sinuosa composición no dista mucho, en el fondo, de la propuesta que consolida el valenciano, Antonio Segura Donat, "Dulk" (Segura, A., 2019), con el título Island memories (Figura 6), en La Peñita, № 6. Con ingenuas trazas y estridente cromatismo resume un imaginario viaje que el artista realiza desde Vik, pueblo islandés, hasta el Puerto de la $\mathrm{Cruz}^{12}$.

Figura 5. Si puedes soñarlo, puedes crearlo

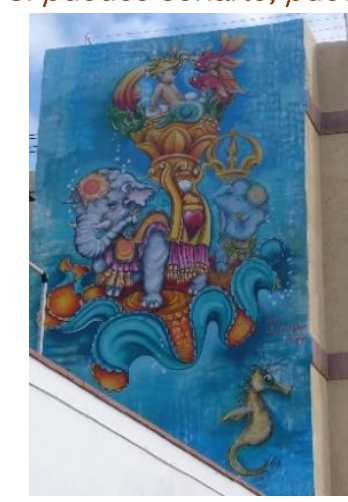

Fuente: Las autoras

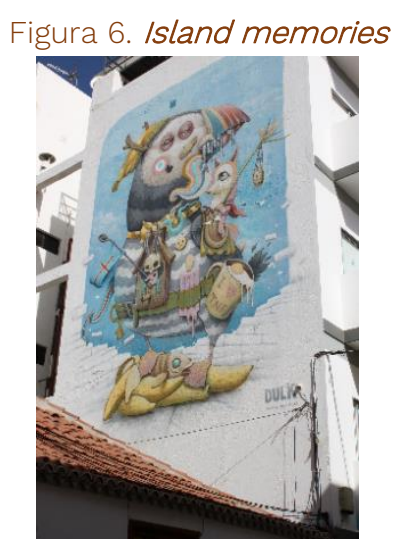

Fuente: Las autoras

El artista de origen francés Louis Lambert, "3TTMAN"13, muestra en el número 28 de la calle El Lomo, un mural que hace alusión a la cultura insular, por la que se siente atraído, ya que como explicó en una ocasión, "Tenerife es la isla donde he estado viviendo los últimos años, me encanta el ambiente y quería rendirle homenaje” (Lambert, L., 2019). Sobre un inmenso fondo rojo, el grafitero plasma, con el significativo título Los Magos (Figura 7), una familia formada por dos progenitores y un menor. Se trata de un autorretrato y de la recreación de una situación que ha vivido recientemente, una obra autobiográfica que expresa sus sentimientos y la necesidad que siente de compartirlos con el público.

Siempre enriqueciéndonos de temáticas y estilos, de la evidencia del caso anterior nos transportamos de nuevo a un mundo onírico, una vez que regresamos a la calle Teobaldo Power y, nos situamos en el no 8, donde la desbordante imaginación de "FEOFL!P"14 nos arrastra con sus Aves volátiles (Figura 8) por un embravecido mar, en el que navega una barca impulsada por remos en forma de pluma. Está ilustrada con símbolos aborígenes y en ella puede leerse "Taoro", denominación del menceyato de la isla al que perteneció el municipio portuense (FEOFL!P., 2019). Y de la ensoñación regresamos a la realidad más acusada, cuando tan solo unos pocos inmuebles más allá, concretamente en la medianera del № 16, nos deslumbramos con la fidelidad del retrato

\footnotetext{
11 Su producción suele expresar escenas que parecen surgir de la fantasía infantil, recurriendo para ello a coloristas muñecos que se mueven en teatrales escenarios. Se trata de una artista versátil y así lo ha demostrado incluso en Puerto Street Art, pues aparte de aportar este mural, en posteriores ediciones, tal como veremos más adelante, participa recreando los motes de algunos vecinos en las fachadas de sus viviendas.

12 Antonio Segura Donat estudió Diseño Gráfico e Ilustración en Valencia, su ciudad natal, donde cultiva pintura, escultura, dibujo y publicidad. Ha trabajado en Vancouver, Miami, Nueva York, Bruselas, París o Chicago. Su producción se mueve en un mundo surrealista colmado de detalles imaginarios que contrapone a los humanos.

${ }^{13}$ Louis Lambert, residente en Bajamar, es un artista polifacético, grafitero, muralista, pinta cuadros y hace esculturas. Es conocido con el alias "3ttman" o "el hombre de tres cabezas", ya que según el propio artista: "es el símbolo que tuvo mi alter ego cuando estuve pintando en la calle. Cada cabeza es un punto de vista de una situación». Sus murales decoran ciudades como Moscú, Atlanta, o Dakar y ha expuesto en México D.F., Arco en Madrid, Londres y Sarajevo.

${ }^{14}$ De origen lanzaroteño se formó en la Facultad de Bellas Artes de La Laguna, ciudad en la que reside.
} 
que Matías Matas "Sabotaje al Montaje"15 hizo de Chucho Dorta, (Figura 9) a quien rinde un tributo de agradecimiento por haber defendido fervientemente las tradiciones insulares, entre ellas el popular "baño de cabras" que se celebra precisamente en el Puerto de la Cruz, en la noche de San Juan, para celebrar el solsticio de verano, al igual que hicieron los guanches. Sin embargo, abandonamos la vía sumergiéndonos una vez más en un mural que aporta íntimas alucinaciones, cuyo significado difícilmente podemos desentrañar. Realizado por Víctor Pacheco, “Kob”16, bajo el título Kobtropical (Figura 10), transforma el costado del inmueble no 28, en una alegre composición, a modo casi de bodegón, de formas de apariencia vegetal, imaginarios animales y seres orgánicos, que se aglutinan y extienden aprovechando la acusada verticalidad del soporte (Pacheco, V., 2019).

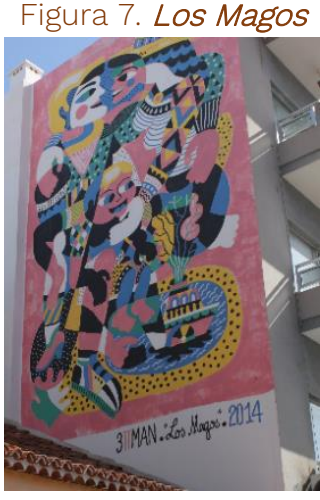

Fuente: Las autoras.
Figura 8. Aves volátiles

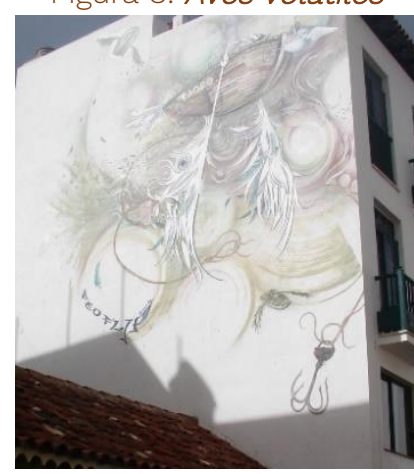

Fuente: Las autoras.

A “Belin", firma artística de Miguel Ángel Belinchón", se le asignó la pared correspondiente al edificio no 17 de la calle Puerto Viejo, sobre la que representa La eterna juventud (Figura 11), alegorizada por el detallista rostro de un marinero, de piel curtida, que sostiene un pequeño barquito de papel. Considerado como uno de los artistas más destacados del hiperrealismo, le gusta trabajar con spray y prescindir de cuadrículas, proyectores y plantillas (M. A., 2019).

Figura 9. Chucho Dorta

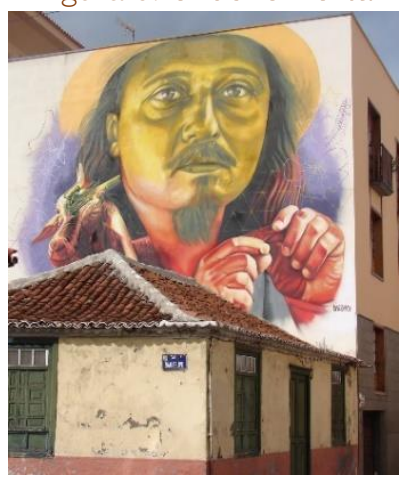

Fuente: Las autoras.

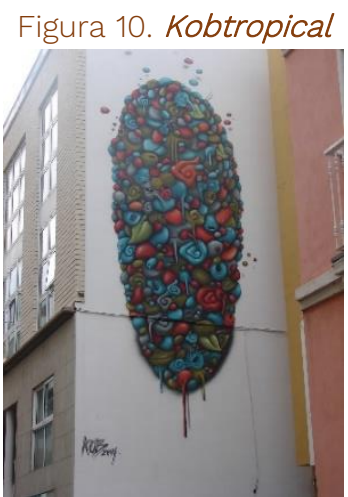

Fuente: Las autoras.

\footnotetext{
${ }^{15}$ Grancanario de origen, lleva desde 1990 participando en eventos nacionales e internacionales: Senegal, Francia, Italia, Berlín, Londres, Barcelona, Madrid, San Sebastián, Sevilla, Valladolid y Asturias. Ha expuesto en el Centro Atlántico de Arte Moderno (CAAM, Las Palmas de Gran Canaria). En los últimos años desarrolla la pintura mural de gran formato. En el primer 10 Concurso Internacional de Artes Urbanas Artaq Festival París\&Berlín, celebrado en 2010, premio de grafiti mural.

${ }^{16}$ Comenzó a dedicarse al grafiti en 1999, en el Puerto de la Cruz, donde nació. Trabaja seres, vegetales y animales híbridos de formas caprichosas, adaptándose a la habitual tipografía de los grafiteros. Actualmente comparte esta actividad con la de tatuador en su isla natal, donde sigue residiendo.

${ }^{17}$ Este artista que ejerce tanto la pintura como la escultura nace en Linares, Jaén, en 1979. Con el transcurrir de los años su estilo ha ido cambiando, cultivando inicialmente la estética impresionista y posteriormente el wildstyles o modes pastel, derivando su producción actual hacia el hiperrealismo, adoptando una línea que él define como «postneocubismo». En sus trabajos podemos encontrar la fusión de diversas dimensiones, el 2D y 3D.
} 
Figura 11. La eterna juventud

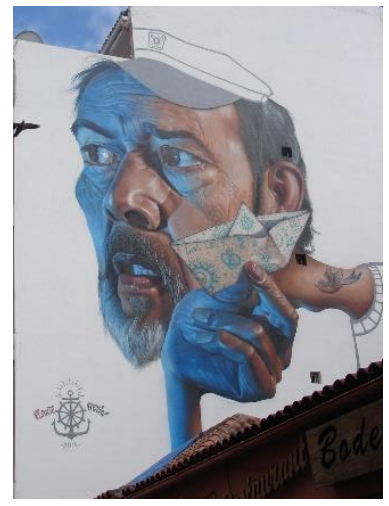

Fuente: Las autoras.
Figura 12. S.T

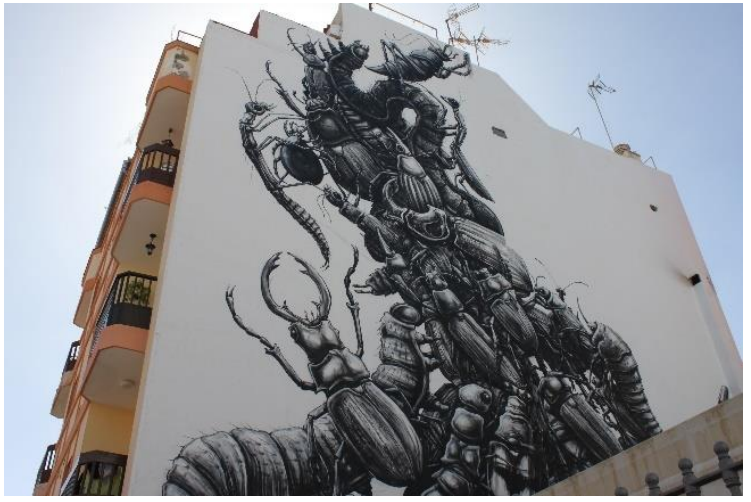

Fuente: Las autoras.

El belga "Roa" 18 opta por un inquietante imaginario de minuciosos insectos cuando se le entrega el muro lateral del edificio que ocupa el Museo Arqueológico del Puerto de la Cruz, en la calle El Lomo, no 7. Un ejército de orugas, escarabajos y saltamontes, pintados tan solo en blanco y negro, parecen decididos a invadir la pared, escalando desde el suelo hasta la azotea (Figura 12). También en el catálogo artístico del grafitero gallego "Liqen", sobresalen especies animales, si bien su visión se centra más en aspectos biológicos, en la evolución de las especies, moviéndose continuamente entre el pasado y el presente (Liqen, 2019); en definitiva, esa es la temática por la que se decanta, cuando se le confía la medianera del inmueble № 3, sito en la calle Cruz Verde, donde plasmó su Ánfora voladora (Figura 13) 19 .

\section{Figura 13. Ánfora voladora}

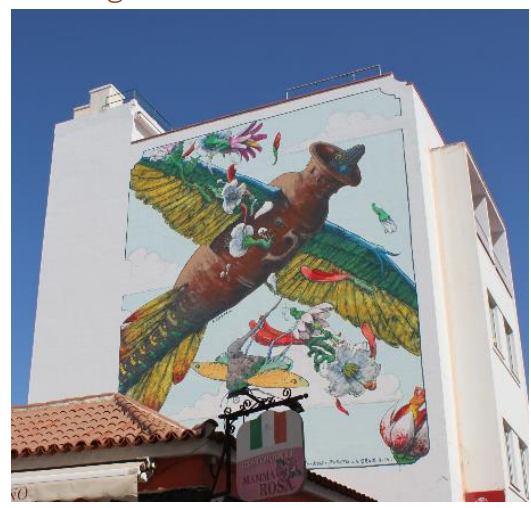

Fuente: Las autoras.

\subsection{Valoración oficial del proyecto}

Una vez finalizada la experiencia, toca reflexionar, y pese al éxito obtenido de cara a los particulares y crítica artística, el Arquitecto Técnico Municipal, Alberto Gutiérrez Hernández, y el coordinador del Área de Cultura del Ayuntamiento del Puerto de la Cruz, Marcelino Martín Encinoso, trabajan conjuntamente para analizar cuáles han sido realmente los logros obtenidos y si la empresa, en

18 Su producción se localiza en muros de Europa, África, América Latina y Estados Unidos, donde ha recreado similar temática a la que exhibe en el Puerto de la Cruz. Se siente atraído particularmente por los espacios abandonados, donde ha desarrollado temáticas que centran su atención en los contrastes: vida-muerte, negro y blanco o ciudad y naturaleza.

19 Obras de este artista de origen vigués, recubren muros de numerosas ciudades, entre otras, Madrid, México, Miami, Tokio, Hiroshima, Nueva York, Berlín y Londres. Su temática analiza la existencia, la condición y en definitiva la vida humana, interpretándolas desde una óptica un tanto misteriosa que deja ver por todo el mundo. 
función de ellos, merecía la continuidad, tal como se había previsto inicialmente, o si se optaba por reconducirla, alternativa que finalmente proponen, en una nueva memoria que data de marzo de 2015. Antes de comentar la reorientación propuesta, debemos centrarnos por su interés, en la valoración técnica, en cuanto que es fundamental para conocer el impacto que la iniciativa alcanzó, o al menos la interpretación que la Administración pública hizo de la misma.

En el informe, tanto el objetivo general como los específicos, fueron analizados uno a uno, llegándose a la conclusión de que se habían cumplimentado con creces, de modo que concluyen dejando claro que el proyecto había reivindicado la tradición cultural del municipio, gracias a "redescubrir la calle como espacio expositivo", y, sobre todo, había servido de gran ayuda para si no transformar, al menos complementar el denominado turismo de sol y playa. Garantizaban entonces que la cultura les suponía un gran potencial turístico, asegurando que se había logrado crear un producto diferenciador frente a otros destinos, hecho que reforzaba la imagen de la ciudad dentro de la marca PuertodelaCruzXperience. Asimismo, les sorprendió la pujante expansión, fuera del ámbito local, de la marca turística Puerto de la Cruz, a través de la prensa escrita, televisión e incluso redes sociales, advirtiendo, por último, que supuso un importante generador de tránsito peatonal, lo que trajo consigo que los viandantes conocieran otros puntos de la localidad que nunca habían visitado, o repararan en otros, ante los que ni siquiera se habían detenido con anterioridad. Es más, consideraron que no solo se habían materializado las expectativas, sino que también se habían generado sinergias recíprocas, capaces por sí mismas de transformar la evolución del proyecto en un acontecimiento más positivo de lo que nunca imaginaron. Entre estas dinámicas simultáneas valoran la conversión de la empresa en un fenómeno capaz de catalizar la ilusión entre los residentes y la facultad de fomentar un "sentimiento de barrio", impresión que a su vez llevó a los propietarios de inmuebles a emprender con recursos propios, otras mejoras de sus fachadas. Pese a lo dicho, consideramos que con gran acierto, el equipo ejecutor tras analizar los factores positivos y detectar los fallos que lógicamente también se dieron, estudia, como ya enunciamos, la conveniencia de mantener los mismos criterios en la continuidad del proyecto, llegando a las siguientes conclusiones: 1ạ, Que en atención a las dimensiones de la localidad, la reiteración excesiva de la propuesta, le haría perder vigor, por lo que sugiere que no se repitiera en más de quince medianeras; 2a , que había que tener en cuenta que el paso del tiempo intervendría en su condición de arte efímero, motivando su reposición a largo plazo, observación que ratificaba la decisión anterior. Partiendo de estos argumentos sugiere, sin perder de vista el objetivo inicial, ampliar las perspectivas del mismo, y transformar la ciudad en un museo contenedor de otras actividades artísticas complementarias.

\section{Reescribir la ciudad en clave de arte. Museo Puerto Street Art}

\subsection{Diseño de un plan museológico. Fases de consolidación}

Ni que decir tiene que la idea primordial de esta iniciativa se basaba en romper la idea convencional del museo cerrado, con el fin de potenciar el espacio público y su estructura física, sin que ello significara renunciar a determinados planteamientos museísticos a la hora de exhibir sus piezas artísticas. Una propuesta que asume conceptos de la nueva museología, en cuanto que se entiende el museo como un ente vivo, tendente a favorecer diferentes relaciones con un público potencial, integrado por distintos grupos sociales (Valdés, M.C., 1999; Pérez, E., 2012). Por esa razón, y en atención a que el visitante conociese de antemano los contenidos y su distribución, una de las sugerencias propuestas radicó en dividir la ciudad en las siguientes "salas":

La Sala I, denominada también "Martiánez. Intervenciones varias", intentaba dar respuesta a la siguiente pregunta ¿puede ser la calle algo más que asfalto, mobiliario urbano y aceras? La réplica 
artística afirmativa correspondería a artistas como "PEJAC" o "OakOak20, entre otros, para los que cualquier tipo de objeto urbano por frío que fuese, -alcantarilla, grietas, cajas de registro de instalaciones- podía transformarse mediante una intervención artística en un elemento capaz de despertar la interacción del viandante, quien se ve obligado a buscar un significado que no siempre es obvio (Oak Oak, 2019).

Bajo el epígrafe, "Puerto de la Cruz Casco. Intervenciones escultóricas en fachadas", la Sala II, trataría de superar la bidimensionalidad que acompaña a la propuesta muralista, incorporando obras escultóricas en las medianeras que bien podrían estar relacionadas con elementos arquitectónicos de edificaciones desaparecidas como muros, arcos..., o cualquier otro elemento antiguo que no fuese ya tan perceptible en la edificación actual.

"La Ranilla. Intervenciones murales", Sala III, como su propia designación indica, agruparía las actuaciones aplicadas en las medianeras durante el año anterior, y otras que en un futuro pudieran complementar el proyecto. Al planificar esta "dependencia”, los promotores se plantean incorporar al recorrido, convirtiéndolo en el punto cero o inicial, el mural localizado en la calle José de Arroyo, n-12, titulado Sol Naciente (Figura 14), obra del tinerfeño Manuel Fernández Padrón. Había sido realizado a principios de los sesenta del siglo pasado, tratándose de una obra única para Canarias, no solo por su ejecución con piedra de mosaico, sino también por su simbología masónica.

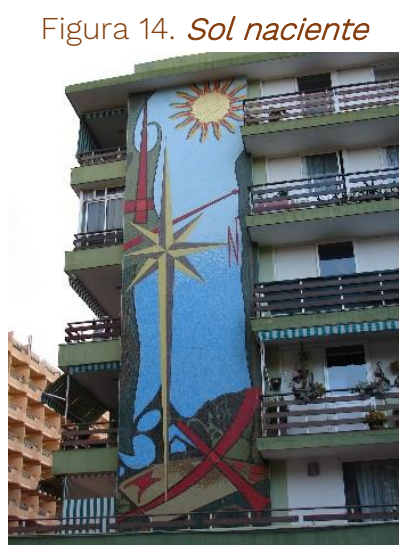

Fuente: Las autoras.

El contenido de la Sala IV, presidida por el subtítulo, "Playa Jardina. Escultura”, partía de la base de que, pese a que el municipio tenía distintas esculturas repartidas a lo largo de su espacio público, este tramo del litoral, habilitado desde años antes con un llamativo paseo ajardinado, podría transformarse en una zona exclusivamente destinada a ella, convirtiéndose el arte en complemento perfecto del entorno natural.

Para la materialización del proyecto, la memoria dedica uno de sus apartados al aspecto que, en tal sentido, tras la experiencia previa, consideran fundamental: la difusión. Así, insistiendo en la idea de que "resultaba tan importante venderla como hacerla", se propone: prestar atención particularmente al gabinete de comunicación para informar a los medios convencionales, elaborar perfiles que singularizasen el proyecto en las redes sociales. Para ello se podía aprovechar a su vez las páginas web de los artistas implicados en el proyecto, diseñar y elaborar vídeos promocionales,

\footnotetext{
20 De origen francés, su actividad artística centra su interés en actuar sobre distintos elementos urbanos, convirtiéndolos en objetos en los que es difícil no reparar, procurando siempre, desde una perspectiva geek, la sonrisa del viandante, que libera así las tensiones que ocasionan los sobrecargados ámbitos de la ciudad moderna. Tras celebrar exposiciones individuales en Newcastle, París y Lyon exhibe parte de su producción por primera vez, en 2015, en América del Norte, en la Galería Vertical, de Chicago. Su trabajo ha sido publicado en dos libros, uno en EditionPopulaire (2011) y el otro en EditionsOmaké.
} 
trípticos informativos y contenido web, así como plantear programas de señalización informativa en la vía pública.

La crisis económica que afectaba durante esos momentos a la economía nacional, y que tanta incidencia alcanzó en el sector cultural, provoca que el cronograma de desarrollo y financiación del proyecto quede mediatizado por la cautela, estableciendo un programa institucional anual a largo plazo, articulado a su vez en dos grandes etapas. La primera, denominada "Fase de creación e implantación", a desarrollar durante los primeros cinco años, daba por ejecutada la etapa inicial con el diseño y ejecución, el año anterior, de la Sala III, es decir la relativa a los murales. Durante el segundo, -entonces vigente- se potenciaría dicha dependencia, al menos con una obra más, y se encargaría la primera actuación escultórica en fachada, iniciando por tanto la Sala II. En el tercer año, 2016, se daría comienzo a la Sala I, mientras que, en el cuarto, se reforzarían los contenidos tanto de esta última como los de la tercera estancia. Durante el último, 2018, se recuperaría el móvil que César Manrique había realizado en el Complejo Municipal Costa de Martiánez, que diseñara a finales de los años sesenta ${ }^{21}$, y se celebraría una muestra escultórica en la Sala IV, de cuyo contenido se seleccionaría una pieza que pasaría a engrosar los fondos del museo.

La segunda gran etapa, siempre siguiendo las intenciones expuestas por los promotores, debería comenzar a partir del sexto año, entendiéndose como "Fase de consolidación". Además de incorporar piezas en atención a las posibilidades y necesidades se plantean emprender la recuperación y mantenimiento de los contenidos, cuestión que estiman tan necesaria como la adquisición de obras nuevas. Para la financiación de este segundo periodo se piensa en la posible cooperación de la iniciativa privada y los patrocinios culturales, sin olvidar tampoco otros procedimientos como el crowfunding, "método que llegado el nivel de madurez y aceptación del proyecto por la población parece adecuado como medio de financiación complementario" (Oficina Técnica del Ayuntamiento del Puerto de la Cruz, 2017).

\subsection{Puesta en marcha y futuro del museo}

Aprobada la creación del museo, se daba comienzo en 2015, al segundo año de la fase relativa a su diseño, aunque como veremos, la implantación y organización del mismo no responderá en lo sucesivo a la secuenciación comentada. De las dos intenciones propuestas para este año, la incorporación de esculturas en las medianeras quedará sin efecto, centrándose en la ampliación de la Sala III. En su recorrido, además de incorporar el mural ya citado, Sol naciente, se agregan en octubre, coincidiendo con la celebración de PERIPLO, dos nuevas recreaciones. En una, situada en la medianera de la calle Carrillo nํㅜ, sobresale por su gran fuerza expresiva, el personaje catalizador de Urban Warrior (Figura 15). Ha sido considerado por la crítica como uno de los murales más sobresalientes de este proyecto. Es más, también está catalogado en una selección internacional, como uno de los mejores del mundo, lo que sin duda supone una beneficiosa publicidad añadida, sobre todo de cara al ámbito de los especialistas en este tipo de evento. Fueron sus autores "Pichi \&Avo"22, cuyas obras se caracterizan por un minucioso realismo filtrado por ideales estéticos surrealistas ("Pichi \&Avo", 2019). El argentino "Martín Ro", desarrolla también en esa misma edición, en la calle José de Armas no 6, bajo dicción hiperrealista combinada con elementos fantásticos, Hay canarios... y canarios (Figura 16); sobre un sicodélico fondo sobresale una mano que sostiene dos pájaros de la especie que da nombre al mural (Martín R, 2018).

\footnotetext{
${ }^{21}$ El complejo Martiánez fue diseñado por el artista lanzaroteño en colaboración con los ingenieros Juan Alfredo Amigó y José Luis Olcina, y con el arquitecto madrileño Fernando Higueras.

22 Firma que corresponde a un dúo de artistas valencianos de gran trayectoria internacional que trabajan juntos desde 2007, algo inusual en el mundo del grafiti. Sus proyectos revelan destreza para favorecer el diálogo entre arte, arquitectura y escultura, incidiendo particularmente en las relaciones que las distintas artes deben establecer con el espacio público. Estilísticamente sorprenden por los logros de un acentuado realismo, filtrado por narraciones de claros componentes surrealistas.
} 


\section{ACE Architecture, City and Environment}

E-ISSN $1886-4805$

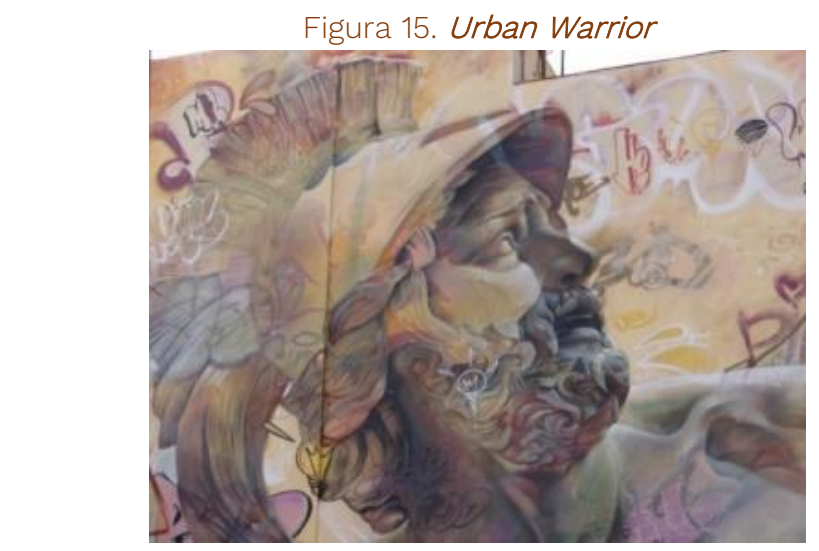

Fuente: Las autoras.
Figura 16. Hay canarios y canarios

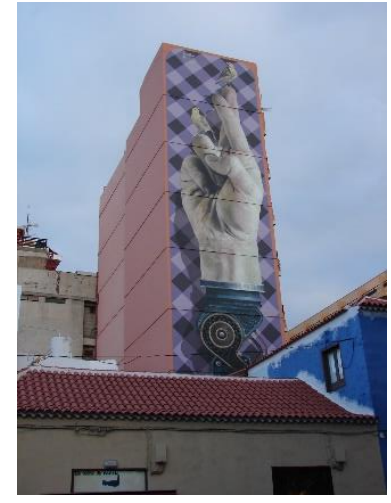

Fuente: Las autoras.

\subsubsection{Un nuevo modelo de gestión: la plataforma Puerto Street Art}

En enero de 2016, el Área de Cultura del Ayuntamiento replantea una vez más el proyecto. La primera decisión adoptada radica en constituir una plataforma de trabajo integrada por otros representantes, tanto municipales como de otros organismos públicos, entre ellos, Consorcio Urbanístico, Centro de Iniciativas Turísticas, Ashotel y Turismo de Tenerife, a los que deciden sumar otros comisionados de asociaciones, empresarios, artistas y profesionales interesados en un común objetivo: aportar su esfuerzo para la marcha de este y otros proyectos culturales del municipio. La iniciativa se inserta en el marco de actuación de Estrategia Cultural de Puerto de la Cruz 2020 (ECPC2020), táctica que buscaba dotar de mayor centralidad a la cultura y hacer partícipe a la ciudadanía de las políticas culturales del municipio, entre otras prioridades. Se trata, por tanto, de un método basado en la co-gestión, siguiendo así, dado sus buenos resultados, el modelo de actuación de los festivales MUECA y PERIPLO, eventos, por cierto, de los que deciden emanciparse con el ánimo de subrayar la autonomía de Puerto Street Art (Oficina Técnica del Ayuntamiento del Puerto de la Cruz, 2017).

Pese a esta última decisión, suponemos que, condicionados por la inmediatez de estos eventos, ya organizados, ese año continúan rigiéndose por la tentativa original, de modo que en mayo, coincidiendo con MUECA se daba inicio a la Sala I, "Martiánez. Intervenciones varias", con las actuaciones de "OaKOaK", que tal como se había supuesto, transformaron, para sorpresa del viandante, los pasos de peatones y parte del mobiliario urbano en divertidas composiciones.

Fue en octubre, en el marco de PERIPLO, cuando se incorpora un nuevo mural a la Sala III, realizado por el burgalés Sebas Velasco ${ }^{23}$, quien recurre a la representación de la figura humana como eje fundamental de un trabajo que titula Revellion der Träume, (Figura 18), localizado en la calle Teobaldo Power, no 4. Se trata del retrato masculino de un rubio joven de piel blanquecina, recortado sobre una perspectiva nocturna de una ciudad. Sugiere situarnos ante un extranjero, probable alusión al papel jugado por el turismo en el desarrollo de Puerto de la Cruz (Velasco, S., 2019). Tras su incorporación, con el fin de no saturar el casco urbano, se da por concluida esta tercera dependencia museística, considerando entonces la posibilidad de extender a los barrios, de forma itinerante, el radio de estas actuaciones.

\footnotetext{
${ }^{23}$ La obra mural de este joven licenciado en Bellas Artes, nacido en 1988, en Burgos, se localiza en Córdoba, Burgos, Vitoria Gasteiz, Brno.... Actualmente vive y trabaja en Donostia. Entre los numerosos premios que ha recibido figuran el Primer Premio en el IX Internacional de Pintura Rápida de Covarrubias, Burgos, y el Primer Premio en el XXIII Certamen de pintura rápida, Jardines de Albia en Bilbao.
} 


\section{ACE Architecture, City and Environment}

E-ISSN 1886-4805

Figura 17. "OaKOaK". Intervenciones en contenedores de basura

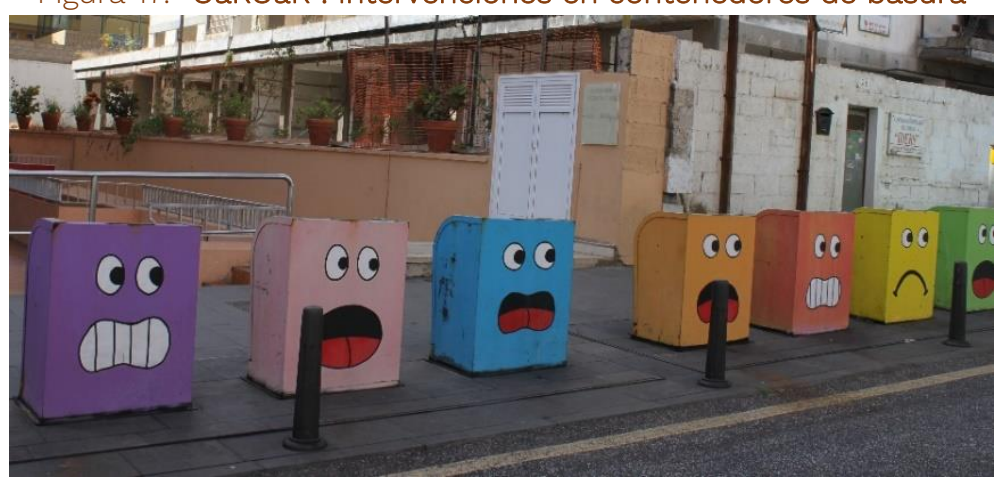

Fuente: Las autoras.

Figura 18. Revellion der traumer

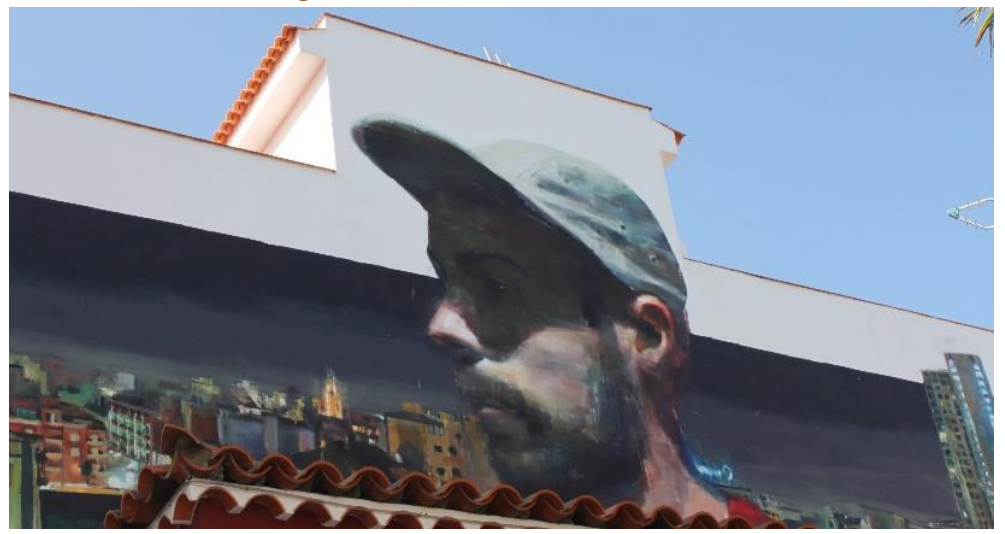

Fuente: Las autoras.

No obstante, la actividad mural se completó con una intervención artística, no contemplada en las memorias iniciales, que llevó a cabo la joven portuense Juliana Serrano. En distintas fachadas de viviendas de La Ranilla, recreó con signos ingenuos pero claros y contundentes, los motes con los que fueron o son conocidos popularmente sus propietarios. Estas pinturas, al contrario que los murales son de reducido tamaño, aunque perfectamente visibles, ya que se encuentran por lo general a la altura del transeúnte que, previamente vislumbra el inmueble en cuestión, por el singular enmarcado que, a modo de esgrafiado, ofrecen las puertas de acceso, una decoración que evoca la que antiguamente lucían muchas casas canarias. La acción plástica, bien a mano alzada y pincel, o bien a base de espray y plantilla, confiere al lugar, un aire casi de cuento, una narración sutil elaborada a base de pictogramas, como si de un comic se tratara, que nos hace transitar por el patrimonio inmaterial del barrio, por la historia oral que han trasmitido sus vecinos. Así, una sugestiva tarta, pintada en el frontis del no 8 de la calle El Lomo, nos indica que estamos ante la vivienda de la familia conocida por "los bizcochitos" (Figura 19 y 20), mientras que cinco figuras que marchan a toda prisa referencian la vivienda, en Cruz Verde no 9, de los descendientes de "el cojo correcorre" (Figura 21), y un gracioso ratón, asoma su cabecita en Mequinez 68, situándonos ante el domicilio del clan conocido por "los ratones" (Figura 22), (Visit.Tenerife.Es., 2016, 1m11ss). Una barca, un pescadito, un camión, una pastora con su ganado, o un lagarto, son otros de los distintos dibujos icónicos que podemos encontrar a lo largo de un paseo que nos retrotrae a los humildes orígenes de este núcleo, sencillos blasones que los vecinos lucen con orgullo ante un espectador que puede interpretarlos fácilmente, dejándose perder, o entretener, en un relato que debe mucho a la realidad. La artista justifica su preferencia por las tonalidades azules, a su origen portuense, y apego a la zona costera donde muchos de sus ascendientes trabajaron como pescadores. 
Al año siguiente, 2017, en el contexto de MUECA, Juliana Serrano continúa arrancando sonrisas a los transeúntes con sus ingenuos "nombretes", mientras se ponen en marcha, en la calle Iriarte, otras manifestaciones plásticas dentro de una acción denominada "la Ruta de la Tapa" (Figura 23). Con ese enunciado, podríamos pensar que se trata de un recorrido tendente a potenciar los productos gastronómicos de los numerosos locales de restauración portuenses, práctica muy en boga, por otra parte, en diversos municipios para poner en valor la gastronomía local e incentivar el consumo, tanto de cara a los vecinos como a los visitantes. Pero nada más lejos de la realidad, ya que supone un sutil e irónico juego de palabras que encubre una propuesta artística dirigida por el ya citado Víctor Pacheco, "Kob" y el "Colectivo 4 Bichos", en la que participaron los siguientes artistas: Tanausú alemán, Alexander Carballo, "Zenwars", "Acon”, Jorge Pérez, Idaira del Castillo, Samuel Hernández y Oswaldo Chong. La acepción de tapa, en este caso, no es más que la de una simple cubierta, esa que cierra o aísla a muchos de los elementos que integran la infraestructura urbana, tales como cajetines de luz, de registro, alcantarillas, en los que pese a su evidencia no solemos reparar dado su anodino y repetitivo formato. Las actuaciones de estos creadores convirtieron estos dispositivos en todo lo contrario, en soportes de divertidas recreaciones pictóricas que, por su singularidad, difícilmente puede eludir el espectador que transita por la denominada "Sala Martiánez. Intervenciones viarias".

Figura 19. Vivienda de la familia apodada "Los bizcochitos"

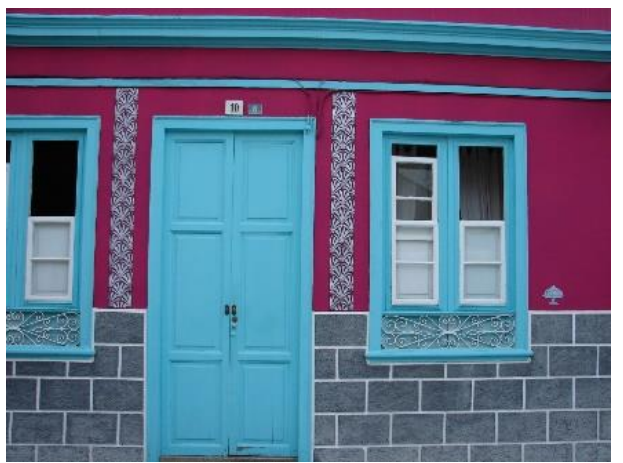

Fuente: Las autoras.
Figura 20. Detalle de la tarta alusiva al mote

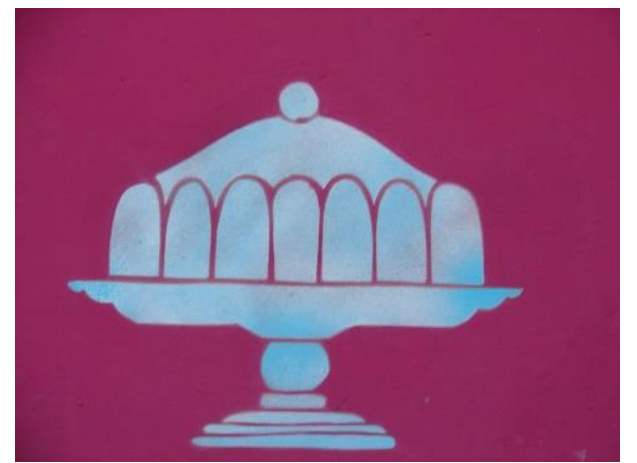

Fuente: Las autoras.

Figura 21. Recreación del mote "el cojo", en la fachada de su vivienda

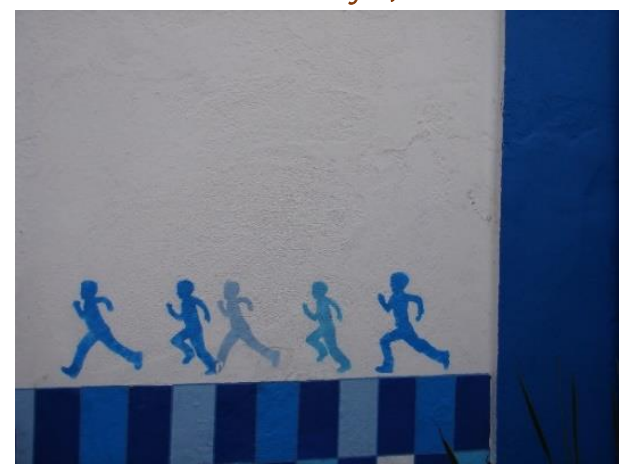

Fuente: Las autoras.

Ese mismo año, concretamente en agosto, la plataforma elabora de nuevo una planificación de acciones a emprender, entre 2018 y 2020, advirtiendo, sobre su carácter abierto y por tanto inconcluso. Se trata más bien de una hoja de ruta que recoge propuestas agrupadas en programas y subprogramas, además de un cronograma de ejecución, así como el presupuesto aproximado de cada una de las actuaciones previstas, y las entidades, organismos y colectivos que podían colaborar en la financiación de las mismas. 


\section{ACE Architecture, City and Environment}

E-ISSN $1886-4805$

Figura 22. Recreación del apodo "los ratones", en la fachada de su vivienda

Fuente: Las autoras.

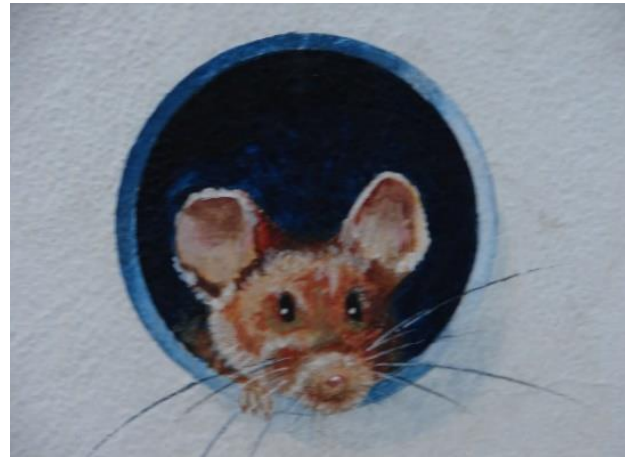

Figura 23. Actuación en "la ruta de la tapa"
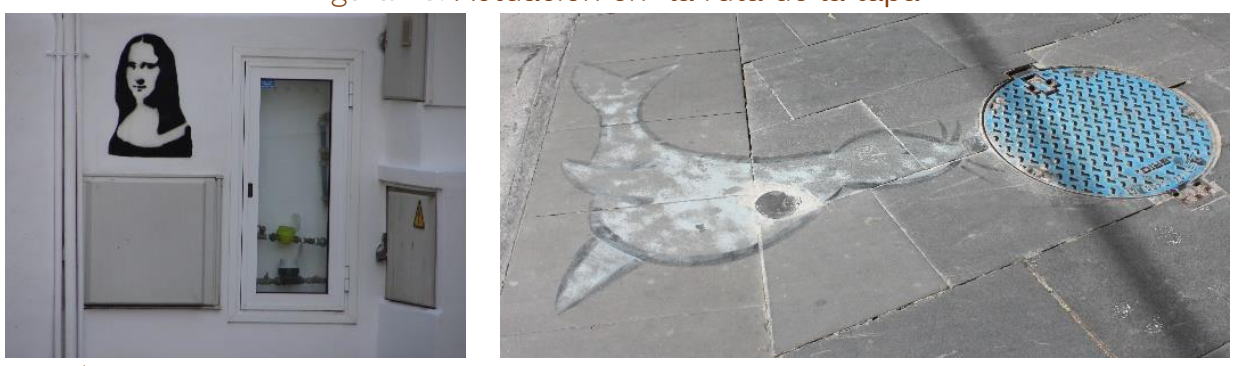

Fuente: Las autoras.

Este nuevo instrumento reitera muchas de las ideas ya expuestas, pero una vez más detectamos novedades respecto a lo formulado en documentos previos. Destacamos, en primer lugar, la posibilidad de incorporar una V Sala, el ya citado Complejo Turístico Municipal Costa Martiánez. Le sobran razones al argumentar que su diseño lo convertían en un espacio de gran valor artístico por sí mismo, ya que este conjunto de piscinas artificiales había sido declarado Bien de Interés Cultural en la categoría de Jardín Histórico, y que su contenido escultórico no era menos interesante, en cuanto que albergaba seis piezas debidas también a César Manrique: Raíces al cielo, Homenaje a William Reich, Homenaje al mar, Barlovento, y dos de sus conocidos Juguetes al viento. Sin embargo, conferir la condición de sala a este espacio destinado al ocio de turistas y población local, exigiría habilitar nuevas fórmulas de gestión, ofertándolo como un lugar abierto, pero hasta hoy, su acceso sigue condicionado al pago de una entrada (Oficina Técnica del Ayuntamiento del Puerto de la Cruz, 2017).

En otro orden de cosas, se insiste en la idea, aún no materializada, de hacer de Puerto Street Art un festival independiente, dotado de una amplia programación de calidad, lo que exigía ampliar los recursos económicos destinados al proyecto. Se tiene en cuenta, que además de los emolumentos de los artistas, de la celebración de actividades paralelas y de la producción en general, se haría necesario contemplar los gastos derivados de la publicidad y promoción. La autonomía del festival requería, por otra parte, la búsqueda de una fecha disponible, tema algo complicado habida cuenta del calendario anual de eventos que celebraba el municipio, por lo que se propone estudiar la posibilidad de agruparlo en torno a otras acciones culturales afines al mismo que se venían desarrollando en el marco de otras actividades como Merkate en Gira o Street Market ${ }^{24}$.

24 Merkate en Gira surge en 2016 a iniciativa del Área de Juventud, Patrimonio Histórico e Igualdad del Cabildo de Tenerife. En colaboración con el Ayuntamiento portuense promueve una especie de supermercado del arte, que pretende dar a conocer al público la obra de artistas noveles, facilitándole su salto a la profesionalización y la recaudación íntegra de sus ventas. Street Market, con idéntica antigüedad focaliza su atención en la dinamización económica y turística del municipio a través de la unión de los comercios para ofrecer sus mejores precios. El término municipal se divide en zonas y cada una de ellas desarrolla una actividad de ocio diferente como pasacalles, hip-hop, juegos malabares, magia, iniciación al surf... 
Uno de los objetivos que ahora se plantean en el que anteriormente apenas habían reparado, radica en hacer itinerar el museo a través de otros barrios o núcleos poblacionales ajenos al casco histórico. Se debate, en tal sentido, entre dos opciones: reproducir en cada núcleo la misma distribución del museo, dimensionándolo en atención a su superficie, zonas e infraestructuras favorables, o diseñar en cada distrito una nueva dependencia del museo destinada exclusivamente a una de las disciplinas propuestas para cada una de las salas habilitadas en el centro. En cualquier caso, las intervenciones en los diferentes núcleos deberán programarse en atención a las potencialidades y singularidades de sus vecinos, además de concretarse mediante prácticas que avalen su implicación en todo el proceso. Esta idea expansionista llevará implícito el acercamiento a distintos colectivos, jóvenes, mayores, discapacitados..., formulando intervenciones en función de sus peculiaridades, con el fin de contribuir a su formación e integración. Esos paradigmas parecen hacerse eco de las acertadas reflexiones que Alguacil publicara sobre la necesidad de buscar la participación vecinal para aprovechar su capacidad sinérgica, una posibilidad que trasmuta sicológicamente el espacio público en un espacio colectivo, permitiendo la apropiación del mismo de manera compartida (2008). O como ha señalado Borja, ese lugar se convierte inmediatamente en un entorno identitario, capaz de asumir enunciados comunitarios (2000).

En definitiva, las acciones a implementar son muchas y variadas, y en ellas se sigue trabajando en la actualidad. Entre las ya concretadas destacamos la continuidad de los apodos en fachadas a cargo de Juliana Serrano, la incorporación del mural cero a la Sala III, las acciones relativas a la promoción del museo, como la edición de un nuevo folleto informativo que incluye todos los murales, la difusión de los mismos a través del Punto de Información Turística, la ubicación de un tótem informativo en cada uno de ellos (Figura 24), donde el espectador, a través de un código QR, puede conocer datos concretos sobre el mural y su autor, consultar los diseños originales, retrotraerse a los momentos de su confección y colocación, o ver imágenes curiosas de la interacción entre artistas, murales y ciudadanía. También se ha llevado a cabo un mapa de identificación de nuevas fachadas y otros espacios para futuras intervenciones: Pirámides Martiánez, estación de servicio DISA, piscina Lago Martiánez, skatepark, locales y solares vacíos...

Entre las muchas propuestas que aún quedan por hacer, entresacamos por su interés, con el ánimo de que lleguen a buen término, la intervención escultórica en fachadas de Mark Jenkins y la de muralistas de la talla de "D*Face", "Daleast" y "Os Gemeos", de estos últimos, gemelos de origen brasileño, Ganz, indica que han sido pioneros en su país, con intuitivas pinturas animadas por personajes fantásticos, "realizados con un estilo que distorsiona el de los cómics tradicionales. Improvisadores natos, sus trabajos reflejan sus personalidades, experiencias y emociones" (2008, pp.84-85).

Asimismo, se considera la realización de homenajes, bien pictóricos o escultóricos, a artistas del grafiti, caso del célebre Juan Carlos Argüello "Muelle"25, o a personajes populares del municipio como "Lázaro el camellero" 26 , sin descartar la posibilidad de perpetuar costumbres o tradiciones

25 Juan Carlos Arqüello Garzo (1965-1995) fue un grafitero de "la movida madrileña" de los años ochenta, que pese a fallecer en plena juventud, dejó su impronta en muchos muros de Madrid, su ciudad natal, primero recurriendo al rotulador de tinta y después al aerosol. Se le conoce por "el muelle", dado que su firma reiteraba esa palabra, coronada por una $\mathrm{R}$ inserta en un círculo, seguida de una espiral rematada en uno de sus extremos por una flecha. El estilo de su tag fue cambiando, al recurrir a distintos colores y formatos de gruesos bordes, con notables sugerencias de tridimensionalidad.

26 Al igual que con el mural ya comentado de Chucho Dorta, con esta otra propuesta, el municipio intenta recuperar la memoria de personajes vinculados a su historia popular, ya que "Lázaro el de los camellos", conocido también como "Lázaro el camellero", fue una figura estrechamente vinculada al desarrollo turístico del Puerto de la Cruz en los años 60. Por iniciativa del entonces alcalde Isidoro Luz Carpenter sacó de su cuadra a sus camellos y los puso a disposición de los turistas. Ataviado con traje típico, los paseaba a través de distintas avenidas, una vez los recogía en la plaza de los Reyes Católicos. Todos los visitantes, famosos o no, querían recorrer el Puerto a lomos de un camello, de modo que Lázaro se convirtió en uno de los vecinos más retratados de aquellos años. 
como la denominada "Mataculebras"27. En otro orden de cosas, se plantea la recuperación de las respectivas esculturas de César Manrique, Roberto Padrón, Alfonso García y Javier Eloy, todos escultores canarios; la elaboración de un proyecto para la creación de una Escuela de Arte Urbano; la modificación de la ordenanza municipal de convivencia ciudadana con el fin de permitir intervenciones artísticas en los espacios públicos; el diseño de un programa de charlas, conferencias y talleres relacionados con actividades urbanas. Especial hincapié se pone en la organización de la I Exposición de la United Buddy Bears en España, subrayando el hecho de que esta muestra, desde que iniciara en 2002, en Berlín, su gira mundial, viene promoviendo la tolerancia, la convivencia pacífica y la comprensión entre los pueblos, las culturas y las religiones.

Figura 24. Tótems informativos de algunos murales realizados

Fuente: Las autoras.

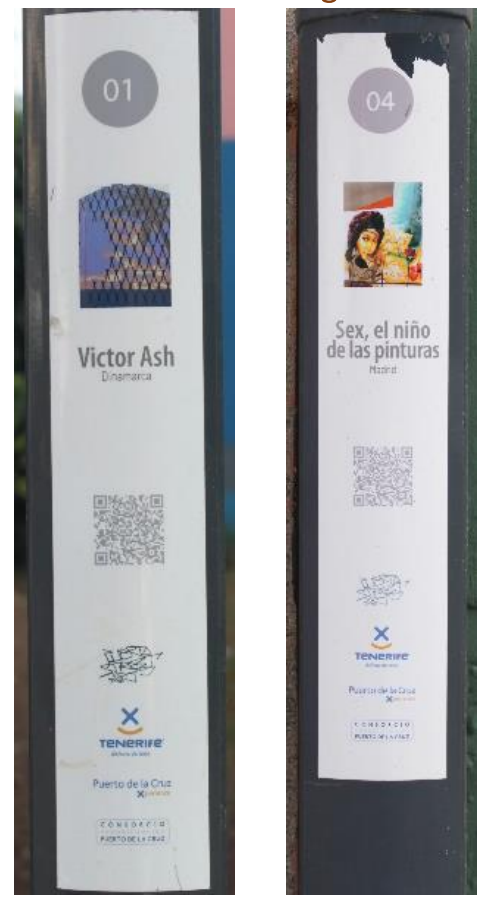

Aunque como hemos dicho el trienio de actuación se cierra en esta memoria en el 2020, los promotores proponen otra actividad a realizar al año siguiente, una prueba más de las intensas ganas de renovar el espacio público de Puerto de la Cruz, para convertirlo en reflejo de las distintas tendencias artísticas que pueden tener cabida en un entramado urbano. Se trata de la realización de obras murales que puedan ser contempladas desde cierta altura o desde el aire, por ejemplo, desde el vuelo de un parapente. Estas intervenciones que tendrían lugar en espacios públicos o privados de grandes dimensiones, zonas de aparcamiento, aéreas de aterrizaje de parapentes, grandes azoteas, o cubiertas y terrazas, podían conformar la Sala VI, una vez consolidado el museo. Ánimo e ideas no les faltan a los organizadores, así que confiamos en que la empresa llegue a buen término con las sugerencias propuestas o con otras que, con idéntico sentido, se propongan para dinamizar la cultura urbana del municipio.

27 Un ejemplo más de las fructíferas relaciones entre Canarias y América, es la pervivencia en el ámbito del municipio portuense de una tradición denominada "Mataculebras", un ritual introducido a finales del siglo XIX, por emigrantes tinerfeños tras regresar de Cuba, donde se interpretaba por esclavos africanos, intentando escenificar la lucha contra el mal. En realidad, era una representación burlesca a cerca de la injusticia del sistema esclavista. Los ñañigos, como se conocían a los esclavos negros eran comandados, en el rito, por un mayoral blanco que con un látigo simulaba matar una culebra que simbolizaba al diablo. Acompañaban sus movimientos con unas reiterativas palabras: "Cabezón son son; que la culebra la mato yo". 


\section{Conclusiones}

A tenor de lo expuesto podemos concluir, que Puerto Street Art es un proyecto destinado a mejorar el entorno urbano que se ha ido enriqueciendo a lo largo de sus ediciones, y que sin duda continúa vivo, gracias al trabajo conjunto de la plataforma. En este modelo de gestión, quizá radique el éxito de una iniciativa cultural que ha encontrado en la calle, el soporte idóneo de un museo al aire libre.

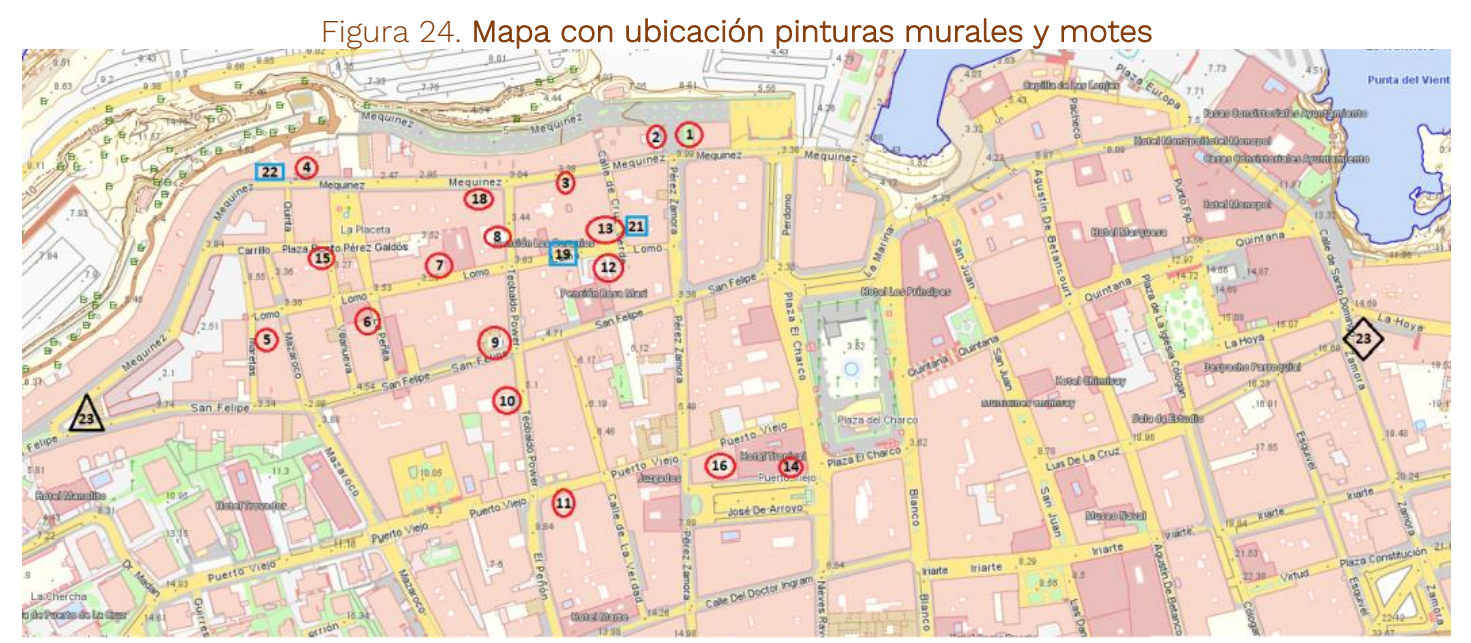

Fuente: Grafcan 1:2.000. Señalización de elaboración propia. Notas; Círculos: Murales, Cuadrados: Motes, Triángulo: Ruta de la tapa, Rombo: Intervención viaria.

Se han emprendido unas acciones que le permiten diferenciarse, tal como se persiguió desde un principio, de otras experiencias de street art. Con ellas, Puerto de la Cruz, recupera su condición como lugar de encuentro, intercambio, y convivencia de vecinos, alejándose del aspecto deshumanizado que iba adquiriendo, gracias una vez más a la cultura, creando sinergias entre distintos eventos que, como el que nos ocupa, han contribuido a dinamizar el desarrollo local, confiriéndole, además, un sello de identidad propio de cara al exterior y, por ende, a los visitantes. Por otra parte, no cabe duda de que la propuesta museística se decanta por la pluridisciplinariedad que favorece el territorio abierto, frente a las posibilidades más reducidas de un museo convencional. La denominada "democracia cultural se hace más factible, logrando la difusión de intenciones de grupos diferentes, la interactividad y una mayor concienciación y diálogo de la comunidad respecto al patrimonio" (Alonso, 1999).

Aunque nuestra intención no ha sido la de cuantificar la repercusión del turismo tras las intervenciones plásticas, opción que requeriría un enfoque diferente, sí queremos dejar constancia de que la implicación de Puerto Street Art en los circuitos turísticos de calidad resulta evidente, ya que podemos encontrarlo publicitado en distintas páginas web del municipio o, en puntos de información turística del mismo (Turismo Puerto de la Cruz. (s.f.). Es más, la consolidación de este acontecimiento como producto, podemos ratificarla, trayendo a colación la página web de Cultania, empresa privada tinerfeña que se ocupa de gestionar el patrimonio cultural de la isla, fomentando su protección, difusión y puesta en valor. Dentro del marco de Canarias en ruta.com, entre los distintos recorridos turísticos que se han ofertado, hemos encontrado Puerto Street Art. El arte de lo urbano, ruta guiada a través de un itinerario de dos horas de duración, que tiene su punto de encuentro en la plaza de la iglesia de Nuestra Señora de la Peña de Francia y que concluye en la plaza del Charco (Cultania, 2018). Con esta iniciativa el municipio se suma a la de otras ciudades de idiosincrasias diferentes que también han apostado estos últimos años por diseñar recorridos que pongan en valor el arte que exhiben en su espacio público, particularmente las muestras de street art, con las que han contribuido a revalorizar el entorno de los viandantes, entre ellas, Nueva Orleans, Buenos Aires, Berlín, Ámsterdam, Madrid, Barcelona y Valencia, por citar algunos ejemplos. 


\section{Agradecimientos}

A la Oficina Técnica del Ayuntamiento de Puerto de la Cruz por la información facilitada sobre el proyecto Puerto Street Art, así como a Matías Matas (Sabotaje al Montaje), comisario de la 1o Edición, quien nos enriqueció, desde su perspectiva artística, los contenidos de esta iniciativa.

\section{Autoría}

Ambas han trabajado conjuntamente en las distintas fases de la elaboración del artículo y en los resultados expuestos

Conflicto de intereses: Las autoras declaran que no existe conflicto de intereses.

\section{Bibliografía}

Alguacil, J. (2008). Espacio público y espacio político. La ciudad como el lugar para las estrategias de participación. Polis, 7(20), 199-223.

Alonso, L. (1999). Introducción a la nueva museología. Madrid, España: Alianza Editorial.

Ariza, A (3 de agosto de 2008). Blogs RTVE.es. [Cuadernos de rodaje]. Recuperado de https://blog.rtve.es/cuadernosderodaje/2008/08/redecora-tu-pueblo.html

Ash, V. (2018). VictorAsh Recuperado de http://www.victorash.net/frontpage/news/

Ash, V. (2018). Victor Ash. Big Art. Recuperado de http://www.victorash.net/

Armas, J.J. (1995). G. Álvarez. Santa Cruz de Tenerife, España: Gobierno de Canarias. Colección Biblioteca de Artistas Canarios.

Barrera M. y Afonso, Y. (2015). Blogs La gaveta voladora. [Blogs de viaje]. Recuperado de https://lagavetavoladora.com/murales-en-puerto-de-la-cruz-puerto-street-art/

Belinchón, M. A. (2019). Belin. Miguel Ángel Belinchón. Recuperado de https://belin.es/\#artstudio

Borja, J. (2000). Ciudadanía y espacio público. En D. Jiménez (coord.), Laberintos urbanos en América Latina. (pp.9-34). Quito, Ecuador: Editorial ABYA-YALA.

Castro Morales, F; Peralta Sierra, Y; Quesada Acosta, A. Mạ. (2011). Tradición y Experimentación Plástica. Dinámicas artísticas 1939-2000. Tenerife, España: Gobierno de Canarias.

Consorcio Rehabilitación Puerto de la Cruz. (2014). Proyecto Piloto de mejora del entorno urbano mediante intervenciones artísticas en medianeras. Puerto Street-Art. Recuperado de http://consorciopuertodelacruz.com/obras/DOSSIER\%20PUERTO\%20STREET\%20ART\%202014.pdf

Consorcio para Rehabilitación del Puerto de la Cruz, Cultura Ayuntamiento Puerto de la Cruz. (2017). Puerto Street Art. Un Museo al aire libre para estimular la creatividad. Puerto de la Cruz, parte de ti. Recuperado de http://visitpuertodelacruz.es/wp-content/uploads/2017/12/Folleto-PSA-SALA-A.pdf

Cultania. (2018). Canariasenruta.com.puerto street art. Recuperado de http://canariasenruta.com/tours/puerto-street-art/ 
Dávila, J. (5 de diciembre de 2010). Tanques de combustibles para la pasarela. El Día. p.65

Festival Mueca. Recuperado de http://www.festivalmueca.com/

Festival Periplo. Recuperado de https://culturapuertodelacruz.com/festival/periplo

Festival Periplo. Recuperado de http://www.festivalperiplo.com/portfolio page/juliana/

Festival Rural de Creación. Las Eras del Tablero. Recuperado de https://www.festivalrurallaserasdeltablero.es/

FEOFL! P. (2018). Basura $\quad$ visual. Recuperado de https://basuravisual.blogspot.com/search/label/mural

Ganz, N. (2008). Graffiti. Arte Urbano de los cinco continentes, Barcelona, España: Editorial Gustavo Gili.

Gómez Aquilera, F. (2004). Arte y ciudadanía y espacio público. On the w@terfront. Recuperado de https://www.researchgate.net/publication/49114772 Arte ciudadania y espacio publico

González, C. (24 de enero de 2012). Iker Muro. Staf magazine. Iker Muro - Staf Magazinestafmagazine.com/gallery/iker-muro/

González Chávez, C. M. y Quesada, A. Mạ. (2020). Street Art: la pintura mural y la regeneración de la ciudad de Santa Cruz de Tenerife. En XXIII Coloquio de Historia Canario Americana (2018), Gran Canaria, España: Casa de Colón. Recuperado de http://coloquioscanariasamerica.casadecolon.com/index.php/CHCA/article/view/10461

Henar, J. (2009). Street art y escritores de grafitti en el casco histórico de Zaragoza. Una nueva perspectiva artística en la Zaragoza contemporánea: de lo efímero a la voluntad de lo perdurable. En B. Fernández Quesada, B. (coord.); Lorente Lorente, J.P. (coord.). Arte en el espacio público. Barrios artísticos y revitalización urbana (pp. 289-302). Zaragoza, España: Universidad de Zaragoza, Prensas Universitarias de Zaragoza.

Lambert, L. (2019). 3ttman.Agitador de Medio Ambiente. Recuperado de http://3ttman.com/site/

Liqen. (2019). Liqen. Recuperado de https://liqen.org/cumul/

Larraz Mora, F. y García Rodríguez, Mạ A. (2000). Mural 2000. (Documentación inédita).

Machado, B. (2018). Evolución de Sumérgete en Santa Cruz. Memoria facilitada por responsable de comunicación de las relaciones corporativas de la Compañía Cepsa. (Documentación inédita).

Martín, R. (2018). Martín R. Arte Callejero. Recuperado de http://www.martinron.com.ar/

Mata, M. (2019). Sabotaje al montaje. Recuperado de http://sabotajealmontaje.com/

Muñoz, T. (1993). Arte mural urbano. Madrid-1981-1991. España: Universidad Complutense de Madrid.

OakOak. (2019). OakOak. Recuperado el 10 de junio de 2019 en http://www.oakoak.fr/

Oficina Técnica del Ayuntamiento del Puerto de la Cruz (2017). Memoria Puerto Street Art. Planificación 2018-2020. (Documentación inédita).

Pacheco, V. (2019). Kob.Kobtropical. Recuperado de http://kobtropikal.wixsite.com/kobtropikal 
Pérez, E. (2012). El arte sale a la calle. Rev. Arte y Ciudad, no12, 17-34, Madrid, España: Universidad Complutense.

Pichi\&Avo. (2019). Pichi\&Avo. Recuperado de http://www.pichiavo.com/

Rodríguez, R. (2019). Roberto Rodríguez Ro-Ro. Recuperado de http://www.robertorodriguezroro.com/

Ruiz, R. (2019). El NiÑo De Las PINtUrAS. Recuperado de http://elninodelaspinturas.es/index.html

Suárez, R. (coord.) (2007). La ciudad en el museo. Foro de arte contemporáneo (CEMFAC). España: Excmo. Ayuntamiento de Santa Cruz de La Palma.

Segura, A (2019). TheDulk. Recuperado de http://www.dulk.es/about.html

T.G. (5 de julio de 2009). Asalto a los murales. La Provincia/ Diario de Las Palmas, p. 3.

Turismo Puerto de la Cruz. (s.f.). Web Oficial de Turismo de Puerto de la Cruz. Puerto Street Art. Recuperado de http://visitpuertodelacruz.es/puerto-street-art/sala-a-puerto-street-art/

Valdés, Mạ C. (1999). La difusión cultural en el museo: servicios destinados al gran público. Asturias, España: Ediciones Trea.

Velasco, S. (2019). Sebas Velasco. Recuperado de http://www.sebasvelasco.com/

Visit.Tenerife.Es. [Cabildo Insular de Tenerife]. (25 de octubre de 2016). El arte y la artista. Juliana Serrano [Archivo de vídeo]. Youtube. https://www.youtube.com/watch?v= a81qBG5/Yk 